\title{
Bacillus insecticides are not acutely harmful to corals and sponges
}

\author{
Andrew P. Negri ${ }^{*}$, Rochelle M. Soo, Florita Flores, Nicole S. Webster \\ Australian Institute of Marine Science, PMB 3 MC, Townsville, Queensland 4810, Australia
}

\begin{abstract}
Bacillus thuringiensis is a Gram-positive bacterium that produces crystalline endotoxins and is widely considered an environmentally safe insecticide to control mosquitoes and a number of agriculture pests. Bacteria closely related to $B$. thuringiensis have recently been discovered in association with diseased sponges, which has raised concerns that Bacillus insecticides may be harmful to tropical marine invertebrates. We exposed coral larvae and juvenile corals to the insecticides VectoBac $^{\circledR} \mathrm{G}$ (containing B. thuringiensis israelensis) and VectoLex ${ }^{\circledR} \mathrm{G}$ (containing B. sphaericus). VectoBac $\mathrm{G}$ and VectoLex $\mathrm{G}$ had no effect on the survival and metamorphosis of Acropora millepora and $A$. tenuis larvae at very high concentrations $\left(5000 \mathrm{ug} \mathrm{l}^{-1}\right)$. The juvenile corals of the same species were also unaffected after 4 sequential $48 \mathrm{~h}$ exposures to $B$. thuringiensis israelensis and $B$. sphaericus at different stages of development. Adult corals (A. millepora) and sponges (Ianthella basta) were exposed to a single $6 \mathrm{~h}$ pulse of $1000 \mathrm{\mu g} \mathrm{l}^{-1}$ VectoBac G. Although B. thuringiensis israelensis was detected in the seawater using denaturing gradient gel electrophoresis, it was not detected in association with the corals or sponges. No evidence of coral or sponge disease was observed during the following 2 wk. These results indicate that insecticides containing endotoxin-producing Bacillus spp. are unlikely to be acutely pathogenic to corals and sponges. However, the effect on most tropical marine invertebrates remain untested and the risks of seed populations of alien Bacillus becoming established on reefs and horizontal transfer of toxin genes to native bacteria also need to be addressed.
\end{abstract}

KEY WORDS: Insecticide $\cdot$ Bacillus $\cdot$ Coral $\cdot$ Sponge $\cdot$ Larvae $\cdot$ Pesticide $\cdot$ Pollution $\cdot$ Pathogen Resale or republication not permitted without written consent of the publisher

\section{INTRODUCTION}

Bacillus thuringiensis is an endospore-forming Gram-positive bacterium capable of producing crystalline protein $\delta$-endotoxins (Höfte \& Whiteley 1989). These proteins are toxic to several groups of insects and cause necrosis of the gut epithelium that in turn results in starvation and eventual mortality. The use of $B$. thuringiensis is widespread in the tropics, where it is used to control mosquitoes (Lacey \& Undeen 1986) and pests that affect plantations of palm, sugar cane and cotton (Hoong \& Hoh-Christopher 1992, Walker et al. 2003). Commercial B. thuringiensis is generally considered environmentally benign due to its high specificity (Höfte \& Whiteley 1989); however, its effects on tropical marine organisms have not been explored.
Although Bacillus spp. are a common component of marine microbial populations (Ivanova et al. 1999), toxic spore-forming $B$. thuringiensis comprise only a small subset of Bacillus reported in the marine environment (Maeda et al. 2001). Two Bacillus strains were recently isolated from diseased sponges, Ianthella basta, from reefs off Papua New Guinea (Cervino et al. 2006). One strain was most closely related to the group containing $B$. cereus, $B$. thuringiensis and $B$. anthracis, while the other was most closely related to $B$. pumilus (which can be used as a fungicide) (Jacobsen et al. 2004). Simultaneous re-infection of I. basta with 5 isolates (both Bacillus strains and 3 additional Pseudomonas strains) resulted in the onset of disease in this sponge species (Cervino et al. 2006). This result raised concerns that accidental overspray or runoff contain- 
ing commercial Bacillus spp. may contribute to unexplained disease in coral reef invertebrates (Cervino et al. 2006).

To test the potential pathogenicity of commercial Bacillus spp. to important tropical marine species we sequentially exposed larvae and juveniles of the corals Acropora millepora and $A$. tenuis to the mosquitocides VectoBac G containing $B$. thuringiensis israelensis and VectoLex G containing the closely related B. sphaericus. We measured coral larval survival and metamorphosis, and the survival and development of juvenile corals. We also assessed the potential for commercial preparations of VectoBac G and VectoLex G to infect adult $A$. millepora colonies and the sponge I. basta. The coral and sponge exposures mimicked potential exposures by direct accidental overspray or recent runoff with freshly prepared insecticide.

\section{MATERIALS AND METHODS}

Insecticide preparation. Suspensions of bacterial insecticides were prepared in $0.2 \mu \mathrm{m}$ filtered seawater (FSW) from VectoBac G (Bacillus thuringiensis israelensis, Strain H-14 and VectoLex G (Bacillus sphaericus Serotype H5a5b, Strain 2362 (both from Valent BioSciences). Fresh suspensions were prepared $2 \mathrm{~h}$ before each inoculation, maintained at $28^{\circ} \mathrm{C}$ and resuspended by periodic shaking. Subsequent inoculations mimicked events where corals or sponges might be exposed via recent accidental overspray. Exposures were expressed as $\mu \mathrm{g}$ insecticide (VectoBac G or VectoLex G) $\mathrm{l}^{-1}$ and were 10- to 100-fold higher than concentrations that affect target mosquitoes (Brown et al. 2000, Russell et al. 2003).

Coral and sponge collection. Reproductively mature colonies of the 2 broadcast spawning coral species, Acropora millepora (Ehrenberg) and A. tenuis (Dana), were collected from 3 to $5 \mathrm{~m}$ depths at Magnetic Island $\left(19^{\circ} 10^{\prime} \mathrm{S}, 146^{\circ} 52^{\prime} \mathrm{E}\right)$. These corals were maintained outdoors in 27 to $29^{\circ} \mathrm{C}$ flowing seawater in $80 \%$ shaded aquaria at the Australian Institute of Marine Science, Townsville. Gametes were collected and larvae cultured following the methods described in Negri \& Heyward (2000). Following coral spawning, 3 mature colonies of $A$. millepora were fragmented into replicate $8 \times 8 \mathrm{~cm}$ pieces and allowed to acclimate for $1 \mathrm{wk}$. The sponge Ianthella basta (Pallas) was collected from a $15 \mathrm{~m}$ depth at Davies Reef (18 $\left.50^{\prime} \mathrm{S}, 147^{\circ} 38^{\prime} \mathrm{E}\right)$.

Inoculation of larval and juvenile corals and mosquito larvae with Bacillus spp. Coral larval exposures were conducted in sterile 6 -well, $12 \mathrm{ml}$, polystyrene cell culture plates (Nunc) at $28^{\circ} \mathrm{C}$ and $70 \mu \mathrm{mol}$ quanta $\mathrm{m}^{-2} \mathrm{~s}^{-1}$ using compact fluorescent tubes ( $55 \mathrm{~W}$ ) emitting strongly between 420 and $440 \mathrm{~nm}$ under a
$12 \mathrm{~h}$ light:12 h dark cycle. These intensity and spectral conditions mimic sheltered reef habitats of $\sim 8 \mathrm{~m}$ depth where these coral larvae would normally settle. Individual wells contained 10 to 15 Acropora millepora or A. tenuis $6 \mathrm{~d}$ old larvae in $10 \mathrm{ml} \mathrm{FSW}$. Wells from each plate hosted all 4 treatments. To test the effects of Bacillus spp. on a variety of developmental stages, repeated $48 \mathrm{~h}$ exposures were performed (1) on pre-competent (to metamorphose) larvae, (2) when the same larvae became competent, (3) following metamorphosis as azooxanthellate juveniles and (4) once the juveniles had taken up symbiotic zooxanthellae (Table 1). The FSW was changed daily and larvae of both species were exposed to $0,100,1000$ or $5000 \mathrm{gg} \mathrm{l}^{-1}$ VectoBac G or VectoLex G for each of the stages. Larvae were assessed for survival (still mobile) at $5 \mathrm{~d}$ and survival and metamorphosis at $9 \mathrm{~d}$ respectively (Markey et al. 2007). Larval metamorphosis was induced by the addition of $5 \mu \mathrm{l}$ of crustose coralline algae (CCA) extract (Markey et al. 2007). Juveniles were inoculated with symbiotic dinoflagellates (Symbiodinium spp.) prepared from their parental colonies

Table 1. Acropora millepora and A. tenuis. Dosing regime and coral health assessments at different larval and juvenile stages. Both species were repeatedly dosed throughout their development with $0,100,1000$ or $5000 \mu \mathrm{g}^{-1}$ VectoBac G (VB) (Bacillus thuringiensis israelensis) for each larval stage. In addition, $A$. millepora larvae were dosed with the same concentrations of VectoLex G (VL) (B. sphaericus). Seawater was changed in each well on a daily basis. Symbol Y indicates when inoculations occurred. Assessment abbreviations: $\mathrm{srv}=$ survival $; \mathrm{mm}=$ metamorphosis $;$ sym = symbiont uptake; pol $=$ polyp numbers assessed

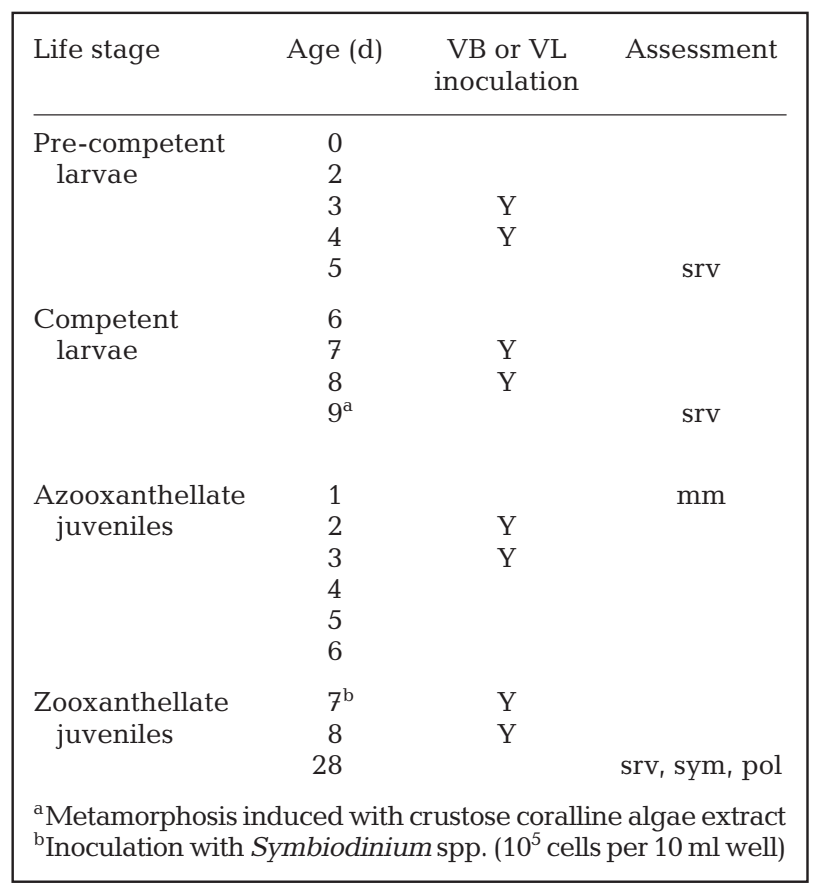


as per the methods described by Owen et al. (2003). Juveniles were assessed for survival and symbiont uptake (Symbiodinium spp. visible in polyps) and the number of polyps per colony counted under a dissecting microscope at $28 \mathrm{~d}$. The efficacy of both VectoBac $\mathrm{G}$ and VectoLex $\mathrm{G}$ were tested against target saltmarsh mosquito larvae (third instar Ochlerotatus vigilax obtained from The Queensland Institute of Medical Research) using assays as described by Russell et al. (2003). Ten O. vigilax larvae were transferred into 4 replicate $150 \mathrm{ml}$ beakers and inoculated with 0 to $1000 \mu \mathrm{g} \mathrm{l}^{-1}$ VectoBac $\mathrm{G}$ or VectoLex $\mathrm{G}$ (under the same light and temperature conditions as for the coral larvae). Survival after $24 \mathrm{~h}$ was indicated by movement of larvae following gentle prodding with a glass pipette.

Inoculation and sampling of sponges and adult corals with VectoBac G. Acropora millepora ( $\mathrm{n}=9$ ) and Ianthella basta ( $\mathrm{n}=7$ ) were placed in partially shaded $(80 \%)$ outdoor, $1000 \mathrm{l}$ flow-through aquaria (1 $\mu \mathrm{m}$ filtered) at $28^{\circ} \mathrm{C}$. Three specimens of $A$. millepora and a single $I$. basta were removed at time $t=0$ as controls. The water flow was stopped and the remaining corals and sponges were inoculated to a final concentration of $1000 \mathrm{\mu g}^{-1}$ VectoBac G. Water flow was maintained with a submerged pump and aeration. Flow-through water was resumed after $6 \mathrm{~h}$ for all treatments. The seawater (1 l) was sampled before inoculation, at $6 \mathrm{~h}$ and again at $14 \mathrm{~d}$ for detection of Bacillus thuringiensis israelensis. The sponges $(\mathrm{n}=3)$ and adult corals $(n=3)$ were sampled for microbes at 1 and $14 d$ and visually assessed for disease at $14 \mathrm{~d}$.

DNA extraction of corals and sponges. Sample tissues (approx. $250 \mathrm{mg}$ ) were aseptically transferred to sterile $2 \mathrm{ml}$ microfuge tubes and $500 \mu \mathrm{l}$ of grinding buffer (2 ml $1 \mathrm{M}$ Tris, $4 \mathrm{ml} 0.5 \mathrm{M}$ EDTA, $2 \mathrm{ml} \mathrm{10 \%}$ sodium dodecyl sulphate [SDS], $400 \mu \mathrm{l} 5 \mathrm{M} \mathrm{NaCl}$ and $11.6 \mathrm{ml}$ distilled water) were added to each replicate sample. Tubes were immersed in liquid nitrogen and ground with plastic pestles. Samples were incubated at $65^{\circ} \mathrm{C}$ for $60 \mathrm{~min}$ before the addition of $187 \mu \mathrm{l}$ of $5 \mathrm{M}$ potassium acetate. Samples were then incubated on ice for $30 \mathrm{~min}$ and centrifuged at $8000 \times g$ for $15 \mathrm{~min}$. The supernatants were transferred to fresh tubes and DNA was precipitated with a $0.8 \%$ volume of isopropanol, washed with $70 \%$ ethanol and resuspended in distilled water.

DNA extraction of seawater. To determine whether Bacillus thuringiensis israelensis was retained in the seawater, 11 samples were filtered through $0.2 \mu \mathrm{m}$ Sterivex filters (Millipore), filled with $1.8 \mathrm{ml}$ lysis buffer (40 mM EDTA, $50 \mathrm{mM}$ Tris and $0.75 \mathrm{M}$ sucrose) and frozen at $-20^{\circ} \mathrm{C}$. Sterivex filter units were then filled with $200 \mu \mathrm{l}$ of lysozyme $\left(10 \mathrm{mg} \mathrm{ml}^{-1}\right)$ and incubated at $37^{\circ} \mathrm{C}$ for $45 \mathrm{~min}$. A $200 \mu \mathrm{l}$ aliquot of Proteinase $\mathrm{K}$ $\left(0.2 \mu \mathrm{g} \mathrm{ml}^{-1}\right)$ in $1 \%$ SDS was added to each sample and the filters were incubated at $55^{\circ} \mathrm{C}$ with rolling for $1 \mathrm{~h}$. The lysates were then recovered from each filter bell into $2 \times 2.5 \mathrm{ml}$ microfuge tubes. The DNA was extracted from all tubes using an equal volume of phenol:chloroform:indoleacetic acid (IAA) (25:24:1, $\mathrm{pH}$ 8.0) and a further extraction with an equal volume of chloroform:IAA (24:1). DNA was precipitated with a $0.7 \%$ volume of isopropanol, washed with $70 \%$ ethanol and resuspended in distilled water.

DGGE. To assess bacterial changes in adult corals and sponges following the addition of $\operatorname{VectoBac}^{\circledR} \mathrm{G}$, all samples were processed for denaturing gel gradient electrophoresis (DGGE). The 16S rRNA gene from each sample was amplified by PCR with universal bacterial primers 1055f: 5'-ATG GCT GTC GTC AGC T-3' and 1406r: 5'-ACG GGC GGT GTG TAC-3' (Ferris et al. 1996). Products from duplicate PCR reactions were combined and applied to a $40 \%$ wt/vol polyacrylamide (37-5:1) gel containing a 50 to $70 \%$ denaturing gradient of formamide and urea. The gel was electrophoresed at $60^{\circ} \mathrm{C}$ for $17 \mathrm{~h}$ in $1 \times$ Tris-acetateEDTA (TAE) buffer at $50 \mathrm{~V}$ using the Ingeny D-Code system. The gel was stained with $1 \times$ Sybr Gold for $30 \mathrm{~min}$, visualised under UV illumination and photographed. Representative bands were excised, re-amplified by PCR with the original primers and checked for correct mobility on another 50 to $70 \%$ DGGE gel. PCR products were sequenced using the forward primer and the PRISM Ready Reaction Kit (PE Applied Biosystems) and ABI 310 and 373 automated sequencers.

Survival of Bacillus insecticides in seawater. Sterile FSW and sterile filtered ultrapure (Milli-Q) water $(0.2 \mu \mathrm{m})$ were inoculated with $1000 \mathrm{\mu g}^{-1}$ VectoBac G or VectoLex $\mathrm{G}$ in 3 replicate 11 flasks. These suspensions were incubated at $28^{\circ} \mathrm{C}$ for $1 \mathrm{wk}$ and subsampled at 2 and $7 \mathrm{~d}$. Serial dilutions of the incubations were spread-plated in triplicate on Marine Agar 2216 (Difco Laboratories) for detection and enumeration of bacterial cells as previously described (Webster \& Hill 2001).

Data analysis. Statistical analyses were performed using STATISTICA 6.0 (Statsoft). Data from larval survival and metamorphosis, and all juvenile experiments were arcsine transformed to meet the assumptions of normality and homogeneity of variance. Differences between means were tested using 1-factor ANOVA. Significant differences between treatment means were assigned at $\mathrm{p}<0.05$. If significantly different, post hoc comparisons of the means for significant factors in the ANOVA were carried out using Tukey's HSD multiple comparisons tests. Untransformed bacterial counts (CFU) taken from different water types at different times were tested using 2-way ANOVA. 


\section{RESULTS}

\section{Effects of Bacillus spp. insecticides}

Coral larvae

The sequential exposure of Acropora millepora and A. tenuis to VectoBac G (containing Bacillus thuringiensis israelensis) and VectoLex G (containing B. sphaericus) at concentrations up to $5000 \mathrm{\mu g} \mathrm{l}^{-1}$ had no observable effect on coral larvae. Mean larval survival was 93 to $98 \%$ for both species after $9 \mathrm{~d}$ in control treatments $\left(0 \mu \mathrm{g} \mathrm{l}^{-1}\right.$ VectoBac $\mathrm{G}$ and VectoLex G ) and this did not change following any of the Bacillus treatments (Table 2). Mean metamorphosis for A. millepora larvae was $87 \pm 5 \%$ (mean \pm $\mathrm{SE}$ ) for the VectoBacG controls and $88 \pm 4 \%$ for the VectoLex G controls, while metamorphosis success was slightly lower for $A$. tenuis VectoBac G controls $(78 \pm 6 \%)$ (Table 2). No significant effect on metamorphosis was observed at VectoBac G or VectoLex $\mathrm{G}$ concentrations up to $5000 \mathrm{\mu g} \mathrm{l}^{-1}$ (Fig. 1, Table 2).

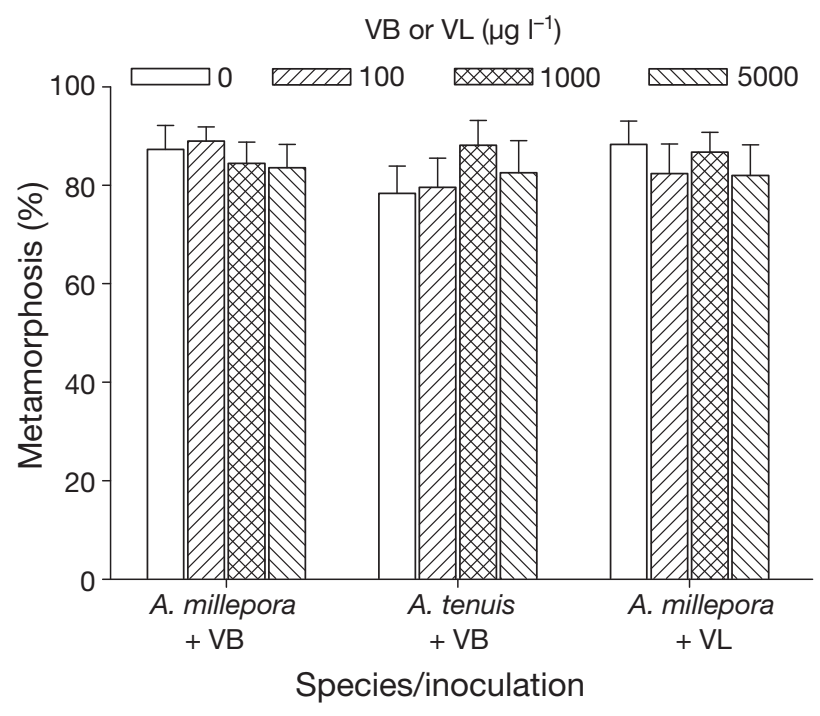

Fig. 1. Acropora millepora and A. tenuis. Metamorphosis of 9 d old juvenile corals following sequential exposure to 0,100 , 1000 or $5000 \mu \mathrm{g} \mathrm{l}^{-1}$ VectoBac G (VB) or VectoLex G (VL) during the pre-competent and competent phases. Bars represent mean percent metamorphosis $(+\mathrm{SE}), \mathrm{n}=6$ replicate wells containing 10 to 15 larvae each

Table 2. Coral larval and juvenile and mosquito larval health statistics. Mean values $( \pm \mathrm{SE})$ for each of the control treatments $\left(0 \mu \mathrm{g} \mathrm{l}^{-1}\right)$ are provided along with ANOVA results $(\mathrm{p}<0.05)$. Larvae and juveniles $(\mathrm{n}=10$ to 15$)$ were assessed from each of 6 replicate wells for corals and 4 replicate jars for mosquitoes. Six juveniles were randomly assessed for polyp numbers (pol, mean $\pm \mathrm{SE}$ ) in each treatment. VB = VectoBac G (containing Bacillus thuringiensis israelensis), VL = VectoLex G (containing B. sphaericus). Assessment definitions: See Table 1

\begin{tabular}{|c|c|c|c|c|c|c|c|}
\hline Species & Insecticide & Stage & Assessment & $\begin{array}{c}\text { Control } \\
(\%) ; \\
\text { Polyps (n) }\end{array}$ & $F$ & df, SS & $\mathrm{p}$ \\
\hline \multicolumn{8}{|l|}{ Corals } \\
\hline \multirow{12}{*}{$\begin{array}{l}\text { Acropora } \\
\text { millepora }\end{array}$} & \multirow[t]{6}{*}{ VB } & Pre-competent larvae (5 d old) & srv & $98 \pm 2$ & 0.0847 & $3,0.0047$ & 0.97 \\
\hline & & Post-competent larvae (9 d old) & srv & $95 \pm 3$ & 0.130 & $3,0.0159$ & 0.94 \\
\hline & & Post-competent larvae (9 d old) & $\mathrm{mm}$ & $87 \pm 5$ & 0.172 & $3,0.0206$ & 0.92 \\
\hline & & Juveniles (28 d old) & srv & $87 \pm 5$ & 0.616 & $3,0.277$ & 0.62 \\
\hline & & & sym & $76 \pm 17$ & 0.376 & $3,0.791$ & 0.91 \\
\hline & & & pol & $3.2 \pm 0.6$ & 0.259 & $3,0.00155$ & 0.85 \\
\hline & \multirow[t]{6}{*}{ VL } & Pre-competent larvae (5 d old) & srv & $98 \pm 2$ & 0.151 & $3,0.0102$ & 0.93 \\
\hline & & Post-competent larvae (9 d old) & $\mathrm{mm}$ & $88 \pm 4$ & 0.287 & $3,0.0461$ & 0.83 \\
\hline & & Post-competent larvae (9 d old) & srv & $93 \pm 5$ & 0.123 & $3,0.0166$ & 0.95 \\
\hline & & Juveniles (28 d old) & srv & $87 \pm 10$ & 0.198 & $3,0.0681$ & 0.90 \\
\hline & & & sym & $85 \pm 11$ & 0.0984 & $3,0.0851$ & 0.96 \\
\hline & & & pol & $2.8 \pm 0.6$ & 0.363 & $3,0.00255$ & 0.78 \\
\hline \multirow[t]{6}{*}{ A. tenuis } & \multirow[t]{6}{*}{ VB } & Pre-competent larvae (5 d old) & srv & $98 \pm 2$ & 0.199 & $3,0.0102$ & 0.90 \\
\hline & & Post-competent larvae (9 d old) & srv & $95 \pm 3$ & 0.423 & $3,0.0395$ & 0.74 \\
\hline & & Post-competent larvae (9 d old) & $\mathrm{mm}$ & $78 \pm 6$ & 0.608 & $3,0.0959$ & 0.62 \\
\hline & & Juveniles (28 d old) & srv & $86 \pm 7$ & 0.292 & $3,0.0777$ & 0.83 \\
\hline & & & sym & $92 \pm 8$ & 0.179 & $3,0.146$ & 0.91 \\
\hline & & & pol & $2.0 \pm 0.5$ & 0.648 & $3,0.00275$ & 0.59 \\
\hline \multicolumn{8}{|l|}{ Mosquitoes } \\
\hline \multirow{2}{*}{$\begin{array}{l}\text { Ochlerotatus } \\
\text { vigilax }\end{array}$} & VB & 3rd instar larvae ( $7 \mathrm{~d}$ old $)$ & srv & $100 \pm 0$ & 257 & $5,12.0$ & $<0.001$ \\
\hline & VL & 3rd instar larvae ( $7 \mathrm{~d}$ old $)$ & srv & $100 \pm 0$ & 25.3 & $5,5.28$ & $<0.001$ \\
\hline
\end{tabular}




\section{Mosquito larvae}

All third instar Ochlerotatus vigilax larvae survived for $24 \mathrm{~h}$ in control treatments (Figs. 2 \& 3A). VectoBac G was highly pathogenic to mosquito larvae, with only $5 \pm 3 \%$ surviving after $24 \mathrm{~h}$ exposure to $30 \mathrm{\mu g} \mathrm{l}^{-1}$ (Fig. 2). VectoLex $\mathrm{G}$ was far less pathogenic to the mosquito larvae with a significant reduction in survival (to $66 \pm 7 \%$ ) observed following exposure to $300 \mu \mathrm{g} \mathrm{l}^{-1}$. These results indicate that both of these Bacillus spp. insecticides were actively pathogenic to their target species.

\section{Juvenile corals}

Juvenile Acropora millepora and A. tenuis survived longer than $28 \mathrm{~d}$ ( 86 to $87 \%$ ) in the absence of VectoBac G or VectoLex G (Table 2). Symbiont uptake by the juveniles was high in control treatments, ranging from $76 \pm 17 \%$ of $A$. millepora colonies to $92 \pm 8 \%$ of A. tenuis colonies in VectoBac G controls (Table 2). The juveniles of both species also developed between 2.0 and 3.2 polyps per colony after $28 \mathrm{~d}$ of development (Fig. 3B, Table 2). There was no effect of VectoBac G or VectoLex G on juvenile survival (Fig. 4), symbiont uptake (Fig. 5) or juvenile development as measured by polyp number at $28 \mathrm{~d}$ (Fig. 6).

\section{Viability of Bacillus insecticides in seawater}

The mean colony forming units (CFU) of Bacillus thuringiensis israelensis isolated from sterile seawater and sterile fresh water inoculated with $1000 \mu \mathrm{g} \mathrm{l}^{-1}$ VectoBac G were $70000 \pm 10000$ and $42000 \pm 5000 \mathrm{CFU} \mathrm{ml}^{-1}$,

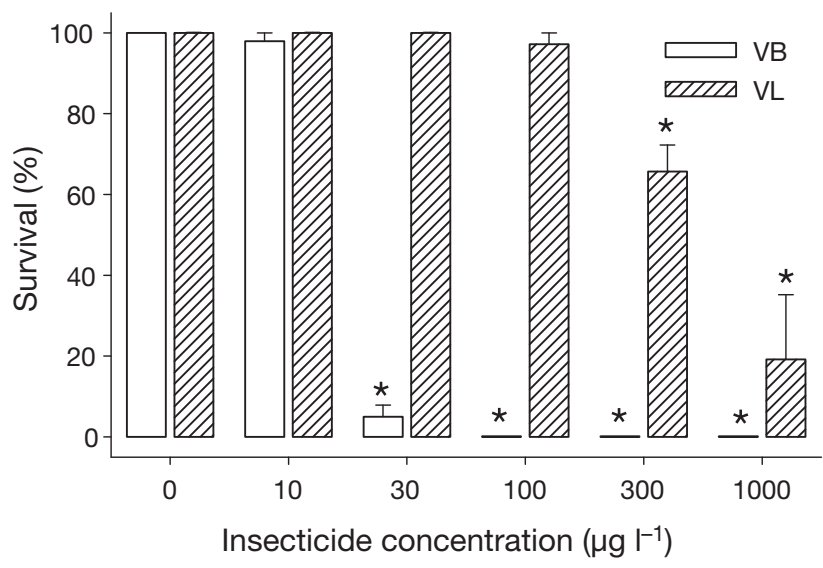

Fig. 2. Ochlerotatus vigilax. Survival of mosquitoes following $24 \mathrm{~h}$ exposures to VectoBac G (VB) or VectoLex G (VL). Bars represent mean percent survival $(+\mathrm{SE}), \mathrm{n}=4$ replicate wells containing 10 larvae each. Asterisk $(*)$ indicates a significantly reduced survival $(p<0.05$, Table 2$)$
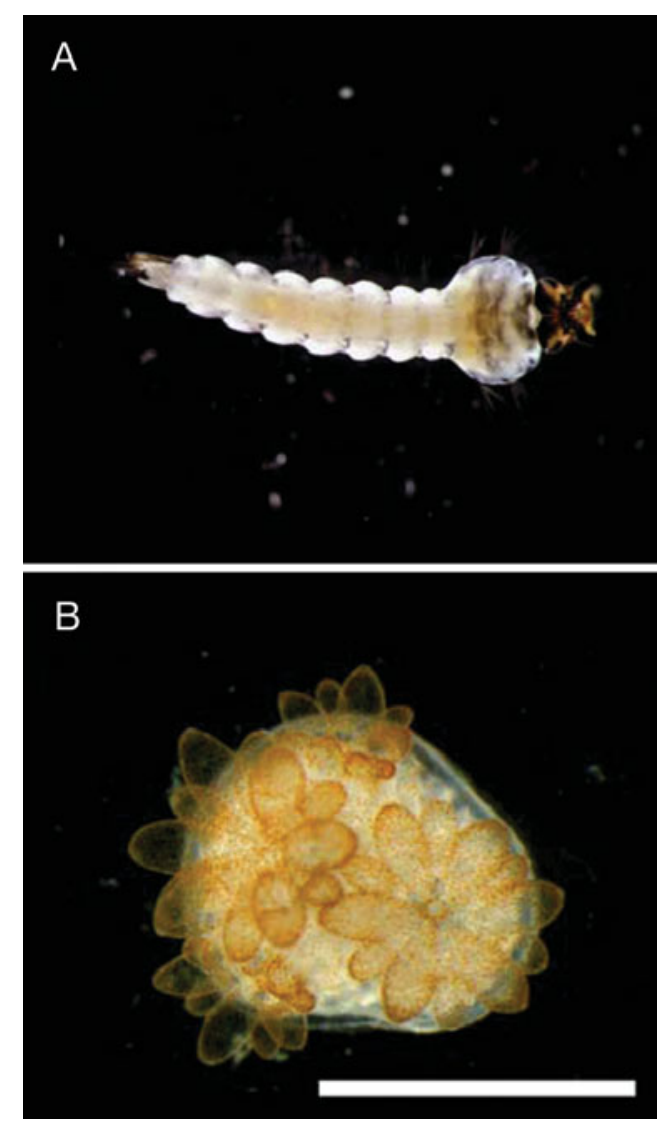

Fig. 3. Species used in assays. (A) Third instar mosquito Ochlerotatus vigilax larvae, a target species of the insecticide VectoBac G (Bacillus thuringiensis israelensis). (B) Nontarget Acropora millepora juvenile coral after $28 \mathrm{~d}$ of development harbouring Symbiodinium sp. This colony had been exposed to 4 sequential $5000 \mathrm{\mu g} \mathrm{l}^{-1}$ exposures of VectoBac G. Scale bar $=500 \mu \mathrm{m}$

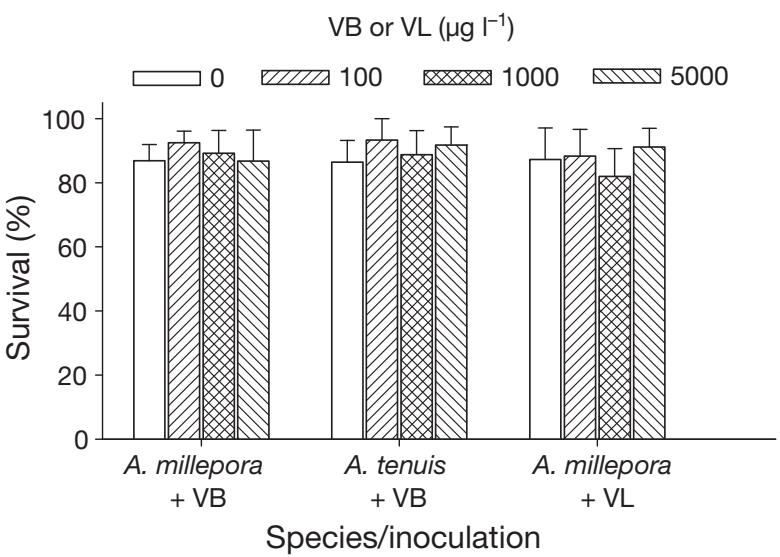

Fig. 4. Acropora millepora and A. tenuis. Survival of $28 \mathrm{~d}$ old juvenile corals following sequential exposure to $0,100,1000$ or $5000 \mu \mathrm{g} \mathrm{l}^{-1}$ VectoBac G (VB) or VectoLex G (VL) throughout the larval and juvenile phases. Bars represent mean percent survival $(+\mathrm{SE}), \mathrm{n}=6$ replicate wells containing 3 to 8 larvae each 


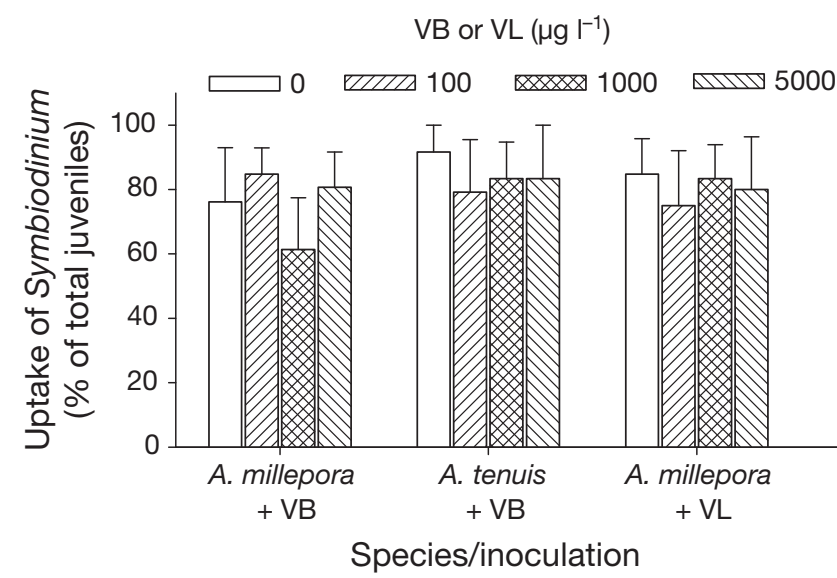

Fig. 5. Acropora millepora and A. tenuis. Uptake of Symbiodinium spp. (\% of juveniles with visible symbionts) in $28 \mathrm{~d}$ old juvenile corals following sequential exposure to $0,100,1000$, or $5000 \mathrm{\mu g} \mathrm{l}^{-1}$ VectoBac G (VB) or VectoLex G (VL) throughout the larval and juvenile phases. Bars represent mean percent uptake of Symbiodinium sp. $(+\mathrm{SE}), \mathrm{n}=6$ replicate wells containing 3 to 8 juveniles each

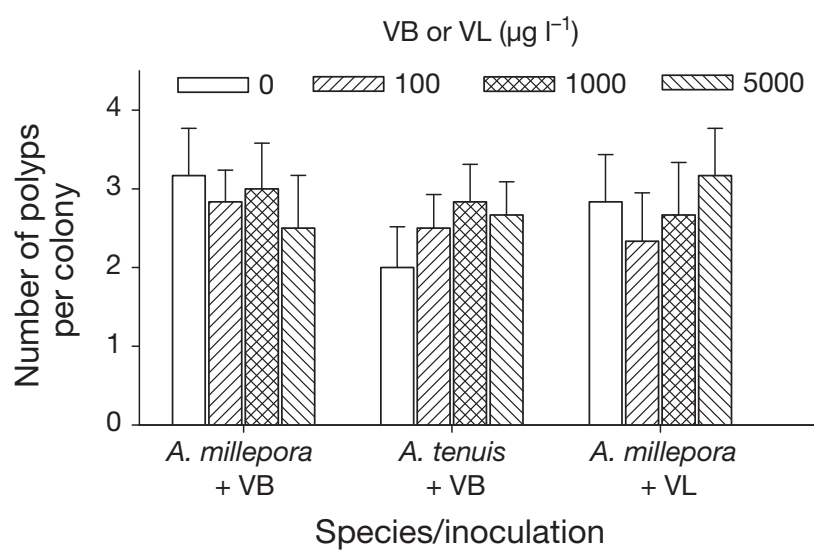

Fig. 6. Acropora millepora and A. tenuis. Number of polyps per juvenile in $28 \mathrm{~d}$ old coral colonies following sequential exposure to $0,100,1000$ or $5000 \mathrm{\mu g} \mathrm{l}^{-1}$ VectoBac G (VB) or VectoLex G (VL) throughout the larval and juvenile phases. Bars represent mean no. polyps per colony $(+\mathrm{SE}), \mathrm{n}=6$ replicate juveniles each

respectively, and this did not change significantly after 2 and $7 \mathrm{~d}$ (Fig. 7, Table 3). Similar colony numbers of $B$. sphaericus $\left(44000 \pm 6000 \mathrm{CFU} \mathrm{ml}^{-1}\right)$ were successfully cultured from sterile seawater inoculated with $1000 \mu \mathrm{g}$ $1^{-1}$ VectoLex G.

\section{Effects of Bacillus thuringiensis israelensis on adult corals and sponges}

The commercial VectoBac $G$ used in the adult exposure contained numerous bacteria as evidenced by

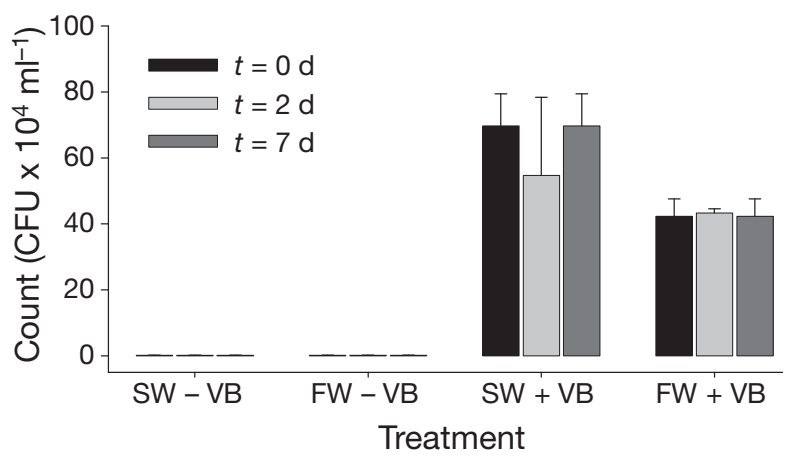

Fig. 7. Bacillus thuringiensis. Counts of B. thuringiensis in control sterile seawater without VectoBac G (SW - VB) and control sterile ultrapure (Milli-Q) water without VectoBac G (FW - VB), and sterile SW and FW after addition of $1000 \mu \mathrm{g} \mathrm{l}^{-1}$ VectoBac G (SW + VB and FW + VB, respectively). Counts are expressed as colony forming units $(\mathrm{CFU}) \times 10^{4} \mathrm{ml}^{-1}(+\mathrm{SE}), \mathrm{n}=3$

the multiple bands present in the crude preparation. The 2 main DGGE bands detected in the VectoBac G preparation had $99 \%$ sequence homology to Bacillus thuringiensis strain SRDD (EF063149) (Band a, EU784823 ) and $99 \%$ sequence homology to B. cereus strain NBRAJATH9 (EU661712) (Band b, EU784824) (Table 4). Both of these bands were identified by DGGE in seawater from the infection tanks immediately after addition of VectoBac $\mathrm{G}$ and after a further $6 \mathrm{~h}$ (Fig. 8). However, they could not be detected in seawater after $14 \mathrm{~d}$ and were not detected in any samples of Acropora millepora or Ianthella basta at any of the sampling times (Fig. 8). No adult I. basta or A. millepora exposed to a single $6 \mathrm{~h}$ pulse of $1000 \mu \mathrm{g} \mathrm{l}^{-1}$ VectoBac $\mathrm{G}$ exhibited observable onset of disease in the present study. The normal symbiotic bacterial community (DGGE bands c-h, Fig. 8) associated with I. basta was not disrupted by the addition of VectoBac G (Table 4).

\section{DISCUSSION}

The Bacillus insecticides VectoBac G (containing $B$. thuringiensis israelensis) and VectoLex G (containing B. sphaericus) were not acutely harmful to non-

Table 3. Statistical results for Bacillus thuringiensis israelensis viability from 2-way ANOVA for colony forming units $(\mathrm{CFU}) \times$ $10^{4} \mathrm{ml}^{-1}$ in sterile seawater (SW) and sterile ultrapure (MilliQ) water (FW) at times $t=0,2$ and $7 \mathrm{~d}$ after inoculation with $1000 \mu \mathrm{g} \mathrm{l}^{-1}$ VectoBac G

\begin{tabular}{|lccccl|}
\hline & SS & df & MS & \multicolumn{1}{c|}{$F$} & \multicolumn{1}{c|}{$\mathrm{p}$} \\
\hline Water type (SW or FW) & 21.8 & 1 & 21.8 & 5.38 & 0.0389 \\
Time $(0,2,7 \mathrm{~d})$ & 1.96 & 2 & 0.981 & 0.242 & 0.788 \\
Water type $\times$ Time & 2.56 & 2 & 1.28 & 0.316 & 0.735 \\
Residuals & 48.6 & 12 & 4.06 & & \\
\hline
\end{tabular}


Table 4. Sequence results of bands from DGGE analysis of Ianthella basta following exposure to $1000 \mu \mathrm{g} \mathrm{l^{-1 }}$ VectoBac G

\begin{tabular}{|llrc|}
\hline Band ID & \multicolumn{1}{c|}{ Nearest relative } & \% similarity & Accession no. \\
\hline A (EU784823) & Bacillus thuringiensis strain SRDD & 99 & EF063149 \\
B (EU784824) & Bacillus cereus strain NBRAJATH9 & 99 & EU661712 \\
C (EU784825) & Gammaproetobacteria from the sponge Halichondria okadai & 98 & AB054161 \\
D (EU784826) & Gammaproetobacteria from the sponge Microciona prolifera & 99 & EF414032 \\
E (EU784827) & Gammaproetobacteria from the sponge Halichondria okadai & 98 & AB054136 \\
F (EU784828) & Unidentified bacterium from oceanic crust & 95 & EU491250 \\
G (EU784829) & Alphaproteobacteria from the sponge Rhopaloeides odorabile & 88 & EU183877 \\
H (EU784830) & Alphaproteobacteria from the sponge Rhopaloeides odorabile & 87 & EU183808 \\
\hline
\end{tabular}

target coral larvae and juveniles at high concentrations (5000 $\mu \mathrm{g} \mathrm{l}^{-1}$ ). Conversely, both Bacillus insecticides were pathogenic to target mosquito larvae at concentrations at least 166-fold and 16-fold lower (for VectoBac $\mathrm{G}$ and VectoLex $\mathrm{G}$, respectively). B. thuringiensis israelensis and $B$. sphaericus germination and survival was confirmed in seawater, yet corals and sponges exposed to high concentrations of VectoBac G did not exhibit any signs of disease after $14 \mathrm{~d}$. It is likely that experimental doses (500 to $5000 \mu \mathrm{g} \mathrm{l}^{-1}$ VectoBac G or VectoLex G) were high compared with concentrations near coral reefs. Concentrations of B. thuringiensis have not been reported from seawater in the vicinity of coral reefs, but if VectoBac G was accidentally sprayed onto a reef in $1 \mathrm{~m}$ of seawater at the recommended application rate of $1.5 \mathrm{~kg} \mathrm{ha}^{-1}$, this would expose corals and sponges to $150 \mu \mathrm{g} \mathrm{l}^{-1}$ VectoBac G (if evenly distributed). These results indicate that the commercial Bacillus insecticides tested are not likely to be acutely harmful to the species tested.

There may be several reasons why VectoBac $\mathrm{G}$ and VectoLex $\mathrm{G}$ did not affect the corals and sponges in the present study. (1) The protein $\delta$-endotoxins of Bacillus thuringiensis (VectoBac G) and B. sphaericus (VectoLex G) are highly specific to a limited number of insect types because solubilisation of the $\delta$-endotoxins is required for toxicity, and this only occurs under highly alkaline conditions (e.g. within mosquito gut) (Höfte \& Whiteley 1989). (2) The high selectivity of these toxins is also dependent on organisms possessing specific toxin binding sites (Gill et al. 1992) that may not be present in the corals or sponges. (3) The ingestion of viable Bacillus spp. from VectoBac $G$ and VectoLex $G$ may not have occurred under the expe-

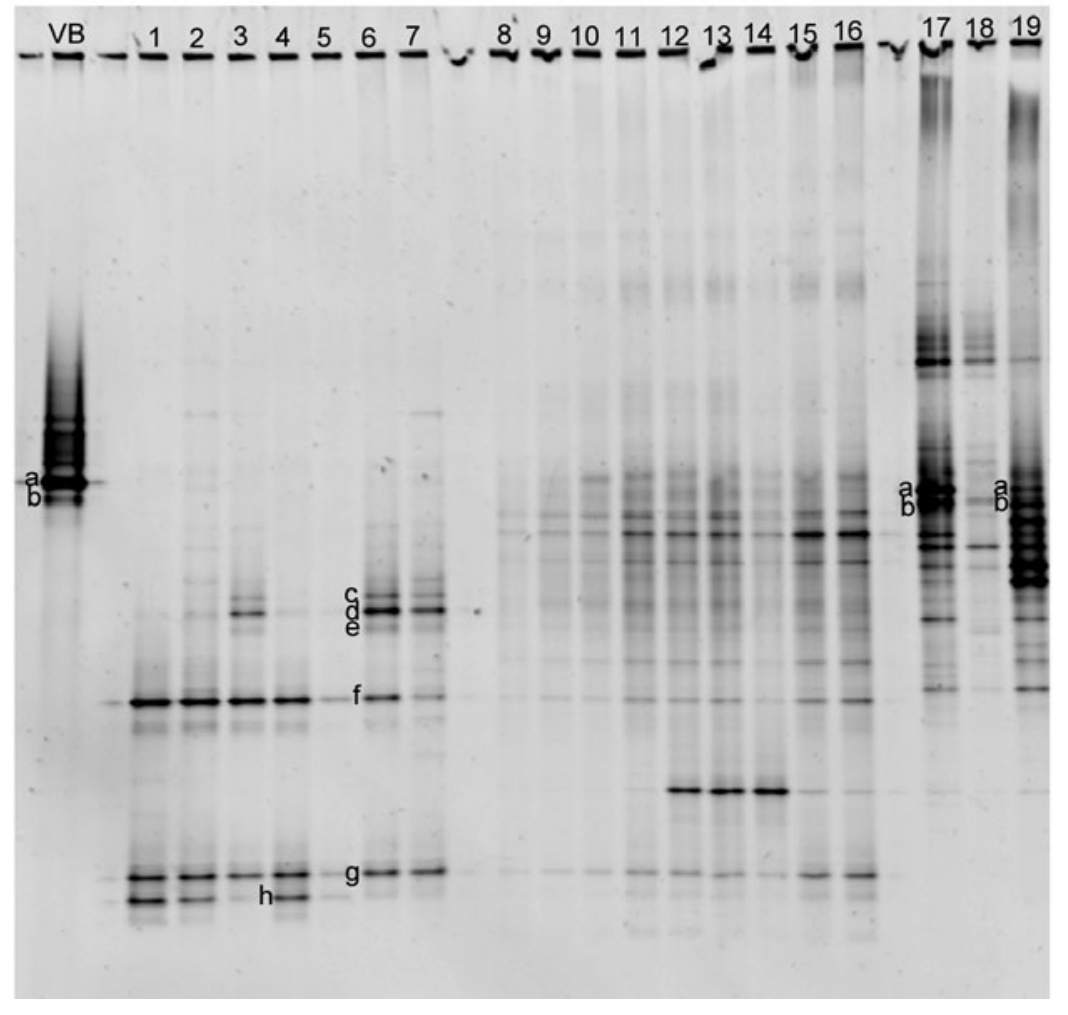

Fig. 8. Denaturing gel gradient electrophoresis (DGGE) of sponges and corals. DGGE profile of $16 \mathrm{~S}$ rRNA-defined bacterial populations from replicate sponge and coral samples exposed to $1000 \mathrm{\mu g} \mathrm{l}^{-1}$ VectoBac G (VB). Lane 7 is sponge at time $t=0 \mathrm{~d}$, Lanes 4 to 6 are sponges immediately after VB addition and Lanes 1 to 3 are sponges at $t=14 \mathrm{~d}$ after VB addition. Lanes 14 to 16 are corals at $t=0 \mathrm{~d}$, Lanes 11 to 13 are corals immediately after VB addition and Lanes 8 to 9 are corals at $t=14 \mathrm{~d}$ after VB addition. Lane 17 is seawater immediately after VB addition, Lane 19 is seawater at $t=6 \mathrm{~h}$ after $\mathrm{VB}$ addition and Lane 18 is seawater at $t=14 \mathrm{~d}$ after VB addition. Bands a to $\mathrm{h}$ have been submitted to GenBank under the accession numbers EU784823 to EU784830 
rimental conditions. (4) The Bacillus strains may have expressed lower $\delta$-endotoxins in full salinity seawater (Nayar et al. 1999). The $\delta$-endotoxins were not analysed during the exposures so the reasons for inactivity are yet to be determined.

No adult Ianthella basta or Acropora millepora exposed to a single $6 \mathrm{~h}$ pulse of $1000 \mu \mathrm{g} \mathrm{l^{-1 }}$ VectoBac G exhibited an observable onset of disease. This result contrasts with the findings from a previous study where paling and necrosis of I. basta were observed following experimental infection using a bacterial consortium consisting of 2 Bacillus spp. and 3 Pseudomonas spp. isolated from diseased sponges (Cervino et al. 2006). There are several reasons why this may be the case. The Bacillus strains isolated in Cervino et al. (2006) may have been different from the commercial strains used in the present study. The sporeforming Bacillus species, including B. thuringiensis, $B$. anthracis (the causative agent of anthrax) and $B$. cereus (a causative agent of gastroenteritis), are closely related and difficult to separate on the basis of 16S rRNA gene sequences (Helgason et al. 2000). The DGGE sequence for $B$. thuringiensis israelensis (EU784823) and the sequence used in the I. basta disease study are not in completely overlapping regions of the 16S rRNA gene. However, where there was overlapping sequence for direct comparison (145 bp) there was $100 \%$ similarity between $B$. thuringiensis israelensis from VectoBac $G$ and strain SDB21A from diseased $I$. basta sponges. The methods of infection also differed between the studies. The present study used a $6 \mathrm{~h}$ passive exposure to suspensions of VectoBac G. This method was used to successfully infect another species of sponge with a natural pathogen (Webster et al. 2002). In contrast, Cervino et al. (2006) attached infected media patches directly to the surface of the sponges for $72 \mathrm{~h}$. Furthermore, Cervino et al. (2006) found that only a combination of 5 bacterial isolates (Bacillus spp. and Pseudomonas spp.) successfully infected the sponges and that the Bacillus spp. isolates alone were not infective.

It is likely that some coral reefs and other sensitive marine environments are periodically exposed to viable Bacillus strains via runoff from agriculture or overspray of mosquito control. Contamination by insecticides containing $B$. thuringiensis israelensis and $B$. sphaericus is also likely to be greatest on reefs already affected by other human impacts such as elevated nutrients and turbidity. Unlike contamination by other insecticides such as chlorpyrifos or endosulfan, Bacillus insecticides are living organisms that may not disappear from ecosystems over years or decades. B. thuringiensis israelensis from the VectoBac G preparation was able to survive well in both sterile seawater and sterile fresh water following $7 \mathrm{~d}$ of incuba- tion (Fig. 7), confirming that accidental exposure of reef organisms to viable VectoBac $\mathrm{G}$ from mosquito control overspray or runoff from agriculture is possible (Cervino et al. 2006). If Bacillus insecticide strains remain viable in marine environments for significant periods of time, they may be triggered into activity and rapid growth under high nutrient conditions or within the gut of non-target species (Hendriksen \& Hansen 2002). Although the overwhelming evidence suggests that Bacillus insecticides are environmentally benign, their effects on most marine invertebrates remain untested.

Acknowledgements. This research was conducted with the support of funding from the Australian Government's Marine and Tropical Sciences Research Facility and the Australian Institute of Marine Science. We thank Darren Alsemgeest from the Townsville City Council for providing the VectoBac ${ }^{\circledR}$ $\mathrm{G}$ and VectoLex ${ }^{\circledR} \mathrm{G}$ samples and Kay Marshall from the Queensland Institute of Medical Research for providing advice on raising Ochlerotatus vigilax larvae. We also thank Eneour Puill-Stephan and Adrian Lutz for their help in the field, Rose Cobb for laboratory assistance and Craig Humphrey for editing advice.

\section{LITERATURE CITED}

Brown MD, Watson TM, Green S, Greenwood JG, Purdie D, Kay BH (2000) Toxicity of insecticides for control of freshwater Culex annulirostris (Diptera: Culicidae) to the nontarget shrimp, Caradina indistincta (Decapoda: Atyidae). J Econ Entomol 93:667-672

Cervino JM, Winiarski-Cervino K, Polson SW, Goreau TJ, Smith GW (2006) Identification of bacteria associated with a disease affecting the sponge Ianthella basta, in New Britain, Papua New Guinea. Mar Ecol Prog Ser 324: $139-150$

Ferris MJ, Muyzer G, Ward DM (1996) Denaturing gradient gel electrophoresis profiles of 16S rRNA-defined populations inhabiting a hot spring microbial mat community. Appl Environ Microbiol 62:340-346

Gill SS, Cowles EA, Pietrantonio PV (1992) The mode of action of Bacillus thuringiensis endotoxins. Annu Rev Entomol 37:615-634

> Helgason E, Okstad OA, Caugant DA, Johansen HA and others (2000) Bacillus anthracis, Bacillus cereus, and Bacillus thuringiensis - one species on the basis of genetic evidence. Appl Environ Microbiol 66:2627-2630

> Hendriksen NB, Hansen BM (2002) Long-term survival and germination of Bacillus thuringiensis var. kurstaki in a field trial. Can J Microbiol 48:256-261

> Höfte H, Whiteley HR (1989) Insecticidal crystal proteins of Bacillus thuringiensis. Microbiol Rev 53:242-255

Hoong HW, Hoh-Christopher KY (1992) Major pests of oil palm in Sabah. The Planter (Malaysia) 68:193-210

> Ivanova EP, Vysotskii MV, Svetashev VI, Nedashkovskaya OI and others (1999) Characterization of Bacillus strains of marine origin. Int Microbiol 2:267-271

> Jacobsen BJ, Zidack NK, Larson BJ (2004) The role of Bacillus-based biological control agents in integrated pest management systems: plant diseases. Phytopathology 94: $1272-1275$ 
Lacey LA, Undeen AH (1986) Microbial control of black flies and mosquitoes. Annu Rev Entomol 31:265-296

Maeda M, Mizuki E, Hara M, Tanaka R, Akao T, Yamashita S, Ohba M (2001) Isolation of Bacillus thuringiensis from intertidal brackish sediments in mangroves. Microbiol Res 156:195-198

Markey KL, Baird AH, Humphrey C, Negri AP (2007) Insecticides and a fungicide affect multiple coral life stages. Mar Ecol Prog Ser 330:127-137

Nayar JK, Knight JW, Ali A, Carlson DB, O'Bryan PD (1999) Laboratory evaluation of biotic and abiotic factors that may influence larvicidal activity of Bacillus thuringiensis serovar. israelensis against two Florida mosquito species. J Am Mosq Control Assoc 15:32-42

Negri AP, Heyward AJ (2000) Inhibition of fertilization and larval metamorphosis of the coral Acropora millepora (Ehrenberg, 1834) by petroleum products. Mar Pollut Bull 41:420-427

Owen R, Knap A, Ostrander N, Carbery K (2003) Compara-

Editorial responsibility: Inna Sokolova,

Charlotte, North Carolina, USA tive acute toxicity of herbicides to photosynthesis of coral zooxanthellae. Bull Environ Contam Toxicol 70:541-548

Russell TL, Brown MD, Purdie DM, Ryan PA, Kay BH (2003) Efficacy of VectoBac (Bacillus thuringiensis variety israelensis) formulations for mosquito control in Australia. J Econ Entomol 96:1786-1791

Walker K, Mendelsohn M, Matten S, Alphin M, Ave D (2003) The role of microbial BT products in US crop protection. In: Medz M (ed) Bacillus thuringiensis: a cornerstone of modern agriculture. Food Products Press, Binghampton, p 31-52

Webster NS, Hill RT (2001) The culturable microbial community of the Great Barrier Reef sponge Rhopaloeides odorabile is dominated by an $\alpha$-Proteobacterium. Mar Biol 138: 843-851

Webster NS, Negri AP, Webb RI, Hill RT (2002) A sponginboring alpha proteobacterium is the etiological agent of disease in the Great Barrier Reef sponge, Rhopaloeides odorabile. Mar Ecol Prog Ser 232:305-309

Submitted: June 11, 2008; Accepted: January 16, 2009 Proofs received from author(s): March 26, 2009 